\title{
Lactic Acid Bacteria Incorporated into Edible Coatings to Control Fungal Growth and Maintain Postharvest Quality of Grapes
}

\author{
Anna Marín \\ Instituto de Ingeniería de Alimentos para el Desarrollo, Departamento de \\ Tecnología de Alimentos, Universitat Politècnica de València, 46022 \\ Valencia, Spain
}

Anne Plotto ${ }^{1}$

U.S. Department of Agriculture, Agricultural Research Service, U.S. Horticultural Research Laboratory, Fort Pierce, FL 34945

\section{Lorena Atarés and Amparo Chiralt \\ Instituto de Ingeniería de Alimentos para el Desarrollo, Departamento de Tecnología de Alimentos, Universitat Politècnica de València, 46022 Valencia, Spain}

Additional index words. Lactobacillus plantarum, biopolymer, population dynamics, starch, casein, postharvest

\begin{abstract}
Lactic acid bacteria (LAB) have been shown to prevent the growth and activity of several postharvest pathogen fungi in fruit and vegetables because of their ability to produce antimicrobial metabolites. Edible coatings (ECs) can be used as carriers of LAB and could provide an alternative natural preservation method. The effectiveness of Lactobacillus plantarum against fungal decay on grapes applied together with EC was studied. Different formulations with or without $\boldsymbol{L}$. plantarum were considered, using pregelatinized potato starch (PS) or sodium caseinate $(\mathrm{NaC})$ as main components of the coating matrices. In some of the formulations, oleic acid (OA) was added as a surfactant. The population dynamics of the bacterium and its ability to control fungal decay were studied together with the assessment of fruit quality. NaC-based formulations improved survival of $L$. plantarum on fruit surface after 7 days of storage in comparison with a water control. On the other hand, $L$. plantarum in PS-based formulation without OA reduced Botrytis incidence more than when applied in $\mathrm{NaC}$ formulation or in water. Coatings had little effect on berry quality (weight, color, firmness, and soluble solids content) of grapes throughout storage, although some of the coated samples maintained acidity and maturity index during storage better than others. Therefore, LAB applied in ECs could provide a viable biocontrol method for postharvest disease in grapes.
\end{abstract}

Fruit spoilage from a variety of fungi is a major cause of economic losses after harvest and during transportation (Hodges et al.,

We are grateful to the Spanish government for the financial support from the national project RTA2012-00067-C02 (Instituto Nacional de Investigación y Tecnología Agraria y Alimentaria, Spain and FEDER funds) and to the Conselleria d'Educació of the Generalitat Valenciana (Spain) for A. Marín's $\mathrm{PhD}$ grant.

Mention of a trademark or proprietary product is for identification only and does not imply a guarantee or warranty of the product by the U.S. Department of Agriculture. The U.S. Department of Agriculture prohibits discrimination in all its programs and activities on the basis of race, color, national origin, gender, religion, age, disability, political beliefs, sexual orientation, and marital or family status.

This manuscript was presented as an oral contribution (HP-12) to the 2018 Florida State Horticultural Society meeting in Fort Lauderdale, FL, June 10-12, 2018.

${ }^{1}$ Corresponding author. E-mail: Anne.Plotto@ars. usda.gov
2011). This may be due to environmental conditions in the field, which can be particularly conducive to fruit infection, but also to inadequate postharvest handling and storage where small wounds on fruit may favor the development of fungal decay (Janisiewicz and Korsten, 2002; Sharma et al., 2009; Spadaro and Gullino, 2004; Trias et al., 2008).

Grapes are one of the most consumed fruits in the world (Ghafoor et al., 2010). Due to their thin pericarp and relatively low $\mathrm{pH}$, grapes are highly susceptible to injuries and colonization by fungi (Aloui et al., 2014). Among the different pathogenic fungi affecting grapes, Botrytis cinerea P. Micheli ex Pers., causal agent of gray mold, is one of the most important problems for grapevines worldwide (Reglinski et al., 2010). Field losses caused by $B$. cinerea can be particularly severe in climates with wet springs and warm and humid summers (Hartman and Kaiser, 2008). Currently, synthetic fungicides applied in the field before harvest, and sulfur dioxide fumigations after harvest remain the common methods to fight gray mold on grapes (Dean et al., 2012; Palou et al., 2010). However, commercial use of sulfur dioxide postharvest presents risks of phytotoxicity on the grape fruit and rachis, and also encounters an increase concern from consumers intolerant to sulfites (Palou et al., 2010). Legislative changes and the increasing concern over the use of synthetic pesticides by consumers, together with the emergence of resistance of some pathogens to fungicides and the high cost of developing new chemical products has promoted an intensive search for alternative methods before and after harvest (Seiber et al., 2014; Usall et al., 2016).

According to Schnürer and Magnusson (2005), biopreservation can be defined as the extension of shelf life and enhancement of safety of foods by using natural or added microflora and their antimicrobial products. In this sense, lactic acid bacteria (LAB) present a promising approach for several reasons: 1) they naturally occur in foods such as fresh vegetables and fruit, 2) are considered harmless to human health, 3) have a GRAS status (generally recognized as safe), 4) are widely used in food industry, and 5) and can act as biocontrol agents due to their ability to produce antimicrobial compounds and to colonize plant tissues vulnerable to infection (Lamont et al., 2017; Roselló et al., 2013; Sathe et al., 2007; Trias et al., 2008). Different low-molecular weight compounds produced by LAB have been reported as effective against several fungal pathogens in the literature: hydroxy derivatives of fatty acids (e.g., palmitic, stearic, oleic and linoleic acids), organic acids (e.g., phenyllactate, lactic, acetic and propionic acids), and cyclic dipeptides (diketopiperazines) (Gupta and Srivastava, 2014; Lamont et al., 2017; Prema et al., 2010; Sangmanee and Hongpattarakere, 2014; Schnürer and Magnusson, 2005; Ström et al., 2002; Yang and Chang 2010).

Lactobacillus plantarum is one LAB species of particular interest and has been isolated in the context of screening antibacterial activity from large LAB collections (Dong et al., 2017; Magnusson et al., 2003). It is a gram-positive, facultative anaerobic and heterofermentative bacterium that can be isolated from a wide range of environmental niches, such as dairy, meat, fermented vegetables, and even oral cavity and gastrointestinal tract of humans and animals (de Vries et al., 2006; Smetanková et al., 2012). Like other Lactobacilli, it is able to grow under aerobic conditions, producing hydrogen peroxide as the final metabolite of its respiratory metabolism (Watanabe et al., 2012). Although the genetic basis for the production of antifungal compounds by this bacterium has not been clearly characterized, several studies have demonstrated its ability to produce hydrogen peroxide, organic acids, phenyllactic acid, cyclic dipeptides, and fatty acids (Crowley et al., 2013; Gajbhiye and Kapadnis, 2016; Sjögren et al., 2003). The presence of multiple antifungal substances, when $L$. plantarum strains are incubated in favorable conditions, 
may explain the broad spectrum of inhibition of this LAB and suggests synergy between compounds.

The use of biopolymer-based coatings to prevent fungal decay of fruit has been extensively reviewed (Marín et al., 2017a; Palou et al., 2015). One of the multiple advantages of ECs is their role in acting as carriers of beneficial organisms producing bioactive compounds, such as LAB. In this context, several studies exploring the incorporation of LAB in coatings and biopolymer-based films have been published (Ebrahimi et al., 2018; Pereira et al., 2016; Sánchez-González et al., 2013). Nevertheless, to our knowledge, no studies deal with the application of biopolymer coatings containing $\mathrm{LAB}$ on grapes with the purpose of controlling fungal decay, although some studies with antagonistic yeasts have been recently reported (Jiwanit et al., 2018; Marín et al., 2016; Parafati et al., 2016).

The objectives of the present work were the following: 1) to study the adherence of $L$. plantarum incorporated to biopolymeric coatings on the fruit surface and its survival over storage under controlled conditions, 2) to test the antifungal activity of $L$. plantarum subsp. plantarum against $B$. cinerea on grapes, and 3) to assess the effect of such coatings on grape quality.

\section{Material and Methods}

Materials. Table grapes (Vitis vinifera L., cultivar Red Globe) were purchased in a local store and selected without signs of mechanical damage or fungal decay. Glycerol was purchased from Panreac Química, S.L.U. (Barcelona, Spain). Pregelatinized PS was provided by Roquette Laisa España S.A. (Valencia, Spain). Tween $85^{\circledR}, \mathrm{OA}$, and $\mathrm{NaC}$ were supplied by Sigma-Aldrich (Madrid, Spain). Man Rogosa and Sharpe (MRS) broth and agar, Potato Dextrose Agar (PDA), and buffered peptone water (BPW) were purchased from Scharlab (Barcelona, Spain).

Microbial strains and culture conditions. The strain ATCC 14917 of L. plantarum subsp. plantarum, originally isolated from pickled cabbage, was obtained from the Spanish Type Culture Collection (CECT; Universitat de València, Burjassot, Valencia, Spain). For long-term storage, the culture was kept in MRS broth containing 30\% glycerol at $-80{ }^{\circ} \mathrm{C}$. The culture was activated by transferring it to MRS broth, until optimal bacterial growth was achieved, as determined by visual broth turbidity and plating serial dilutions in MRS agar. The incubation took place at $37{ }^{\circ} \mathrm{C}$ for $48 \mathrm{~h}$ under anaerobic conditions. Anaerobiosis was created by using anaerobic jars and a $\mathrm{CO}_{2}$-generator system (AnareroGenTM; Oxoid Ltd, Basingstoke, England). Afterward, the inoculum was centrifuged at $4000 g_{\mathrm{n}}$ for $10 \mathrm{~min}$ at room temperature, washed twice with sterile tryptone phosphate water (Scharlab, Barcelona, Spain), and resuspended in $150 \mathrm{~mm}$ glycerol. Then, the inoculum was again incubated at $37{ }^{\circ} \mathrm{C}$ under anaerobic conditions for $3 \mathrm{~h}$ to ensure maximum synthesis of antimicrobial metabolites by the bacterium. A Thoma cellcounting chamber was then used to determine the exact bacterial concentration before inoculating the coating solutions.

The CECT 20518 Botrytis cinerea strain was obtained from the CECT. Before the experiments, the fungus was incubated for $15 \mathrm{~d}$ at $25^{\circ} \mathrm{C}$ on PDA medium. Conidia were scraped from the agar with a sterile loop and introduced in sterile deionized water containing 0.01 Tween $85^{\circledR}$. The conidial suspension was sonicated for $5 \mathrm{~min}$ in an ultrasound bath (Selecta Abrera, Barcelona, Spain) and the final concentration was adjusted to $10^{-4}$ spores/ $\mathrm{mL}$ using a Thoma cell-counting chamber (Cañamás et al., 2011).

Coating formulations. Different formulations of coating-forming dispersions (CFDs) were obtained using $\mathrm{NaC}$ and pregelatinized PS as main compounds. OA was added in some of the formulations as surfactant, with the purpose of improving the CFD wettability and adherence to fruit surface. The CFDs were prepared by dispersing the biopolymers $(2 \% \mathrm{wt} / \mathrm{vol})$ in deionized water for $2 \mathrm{~h}$ at room temperature. After biopolymer dispersion, OA was added at a biopolymer:surfactant ratio of 1:0.1, according to previous studies (Marín et al., 2016). CFDs were homogenized at 13,600 rpm for 4 min using a rotor-stator homogenizer (DI25; Janke and Kunkel, Breisgau, Germany) and sterilized at $121{ }^{\circ} \mathrm{C}$ for $15 \mathrm{~min}$, as preliminary tests revealed microbial growth on nonsterile coating solutions.

After cooling the dispersions, L. plantarum was incorporated into CFDs at a concentration of $5 \cdot 10^{7}$ colony-forming units $(\mathrm{CFU}) / \mathrm{mL}$. This concentration was chosen based on previous studies of biocontrol agents to control B. cinerea on grapes (Marín et al., 2016) and strawberries (Zamani-Zadeh et al., 2014). The CFDs containing LAB were shaken at $150 \mathrm{rpm}$ for $15 \mathrm{~min}$ at room temperature in a rotatory shaker (Selecta Abrera, Barcelona, Spain) to achieve a homogeneous dispersion of the microorganism. A dispersion of bacterium cells in sterile deionized water without coating-forming agents was also prepared at the same cell concentration as one control (C$\mathrm{LAB}$ ). The other control consisted of water with no additive. Preliminary tests showed the coating formulations with or without surfactants had no effect on the pathogen. The different formulations containing or not $L$. plantarum are summarized in Table 1.

Application of CFDs on grapes. Three replicates consisting of five berries each per formulation were used for each assay. Samples were washed with water to remove any sulfur dioxide residue that might affect $\mathrm{LAB}$ and pathogen growth, then drained, dried, and placed separately on sanitized plastic grids. The CFDs were sprayed on the samples for $15 \mathrm{~s}$ using an airbrush (Model S622, Master Airbrush; TCP Global, San Diego, $\mathrm{CA})$ and left to dry at room temperature. Then, the grids were placed in plastic sealed boxes for incubation at $20{ }^{\circ} \mathrm{C}$ and $85 \%$ relative humidity (RH) for 7 or $9 \mathrm{~d}$.
Population dynamics of L. plantarum over storage. The population dynamic of $L$. plantarum supported in CFDs was measured 1 and $7 \mathrm{~d}$ after application. Thus, six replicates per formulation containing the microorganism (three for each time) were considered, and CFDs were applied as described in the previous section. After storage, each replicate was weighed and transferred to erlenmeyer flasks containing $100 \mathrm{~mL}$ sterile $\mathrm{BPW}$, which were shaken at $150 \mathrm{rpm}$ for 20 min. Afterward they were sonicated in an ultrasound bath to achieve the maximum detachment of the microorganism from the fruit surface. Serial dilutions of the washes were carried out in duplicate and plated on MRS agar. The plates were incubated at $37{ }^{\circ} \mathrm{C}$ for $48 \mathrm{~h}$ under anaerobic conditions. Results were expressed as CFU per $g$ of grape.

Effectiveness of $\mathrm{L}$. plantarum against $\mathrm{B}$. cinerea. Before the application of the CFDs, each berry was lightly rubbed with sand paper to weaken its skin and to favor pathogen infection. Formulations containing $L$. plantarum were applied as described previously. An additional control consisting of sterile deionized water $(\mathrm{C}-\mathrm{W})$ was used. After the application of CFDs, the fungal dispersion of $B$. cinerea at $10^{-4}$ spores $/ \mathrm{mL}$ was sprayed with an airbrush for $5 \mathrm{~s}$. Samples were left dry again before incubation at the aforementioned conditions. The antifungal effectiveness of the CFDs containing $L$. plantarum was visually evaluated in terms of incidence (number of berries presenting visible growth of fungal mycelium) and severity (percentage of decayed berry surface in the affected samples) after $7 \mathrm{~d}$ of incubation, as described by Cañamás et al., (2011). Results were expressed as the percentage of reduction of the incidence and severity with respect to that observed in the control sample C-W.

Grape quality parameters. To evaluate the impact of the different CFDs on fruit quality parameters, weight loss and color were measured before application and after $9 \mathrm{~d}$ of storage at $20{ }^{\circ} \mathrm{C}$ and $85 \% \mathrm{RH}$. Firmness, soluble solids content (SSC), and titratable acidity (TA) were measured before the application of the formulations and after $9 \mathrm{~d}$ of storage. In all cases, uncoated grapes were used as a control (C-W).

Weight loss was determined following a gravimetric method and expressed as the percentage loss of the initial weight. Color was measured using a CM-3600d colorimeter (Minolta Co, Tokyo, Japan) with a $10-\mathrm{mm}$ diameter window. To avoid the effect of the fruit surface heterogeneity, measurements were always taken in the same two marked zones of each fruit. CIE-L*a*b* coordinates, hue $\left(\mathrm{h}^{*}{ }_{\mathrm{ab}}\right)$, and chroma $\left(\mathrm{C}_{\mathrm{ab}}{ }^{*}\right)$ were obtained from the reflection spectra of the samples using D65 illuminant $/ 10^{\circ}$ observer. Firmness was assessed with a TA-XT-plus Texture Analyzer (Stable Micro Systems, Surrey, UK), with a $500 \mathrm{~N}$ load cell, using a 10mm-diameter cylindrical probe. The samples were cut longitudinally and $50 \%$ compressed at a $0.2 \mathrm{~mm} / \mathrm{s}$ deformation rate. Maximum force $(\mathrm{N})$ was recorded as firmness parameter. 
After firmness measurements, seeds were removed and berries were homogenized at $3500 \mathrm{rpm}$ for $1 \mathrm{~min}$ and the SSC was measured using a $3 \mathrm{~T}$ ABBE refractometer (Atago Co. Ltd., Tokyo, Japan) at $22{ }^{\circ} \mathrm{C}$. Results were expressed as \% of SSC. For TA, a $10-\mathrm{mL}$ sample was titrated with $0.1 \mathrm{~mol} \cdot \mathrm{L}^{-1}$ to a $\mathrm{pH}$ endpoint of 8.1 using an 800 Dosino titrator (Metrohm, Herisau, Switzerland). Results were expressed as g citric acid per $100 \mathrm{~g}$ of grapes. Maturity index (MI) was calculated as the quotient between SSC and TA. According to several authors, an MI of $\approx 30$ could be considered as optimum for commercial harvest (Nicolosi et al., 2018; Sortino et al., 2017).

Statistical analysis. Analysis of variance (ANOVA) was performed using Statgraphics Centurion XVI version 16.1.17 (Manugistics Corp., Rockville, MD). CFU data were logtransformed before ANOVA to improve the homogeneity of variances. Significant differences were determined using the least significant difference test $(P<0.05)$.

\section{Results and Discussion}

As can be observed in Fig. 1, 1 day after the application of the formulations, counts of L. plantarum were $\approx 5 \log \mathrm{CFU} / \mathrm{g}$. These data agreed with those previously published for the biocontrol agent Candida sake applied on grapes (Cañamás et al., 2011; Marín et al., 2016). The population of $L$. plantarum after $1 \mathrm{~d}$ of application was significantly higher $(P<$ $0.05)$ than the control (C-LAB) when applied in NaC CFD, with and without OA (Log CFU: 5.7 and 5.8, respectively), whereas there were no significant differences in LAB counts between formulations based on PS and CLAB. These results suggest a positive effect of protein coatings on $\mathrm{LAB}$ cell viability when applied on fruit.

After $7 \mathrm{~d}$ of storage, the survival of $L$. plantarum showed a significant decrease when applied without coating-forming agents (C-LAB) and in the case of PS formulation without OA (log reduction of 0.6 and 0.9 , respectively). Both, $\mathrm{NaC}$ with and without $\mathrm{OA}$ and PS with OA formulations showed a better performance at maintaining and/or increasing of $L$. plantarum population on fruit surface. The best result was achieved with $\mathrm{NaC}$, with a final population of $6.2 \mathrm{CFU} / \mathrm{g}$.

Surfactants, such as OA, are usually incorporated in biopolymer coatings with the purpose of improving their adherence to fruit surface. Thus, a higher adherence of the dispersion, and consequently of the microorganism, when OA was present in CFDs could be expected. No clear effect of OA was observed in protein-based formulations, whereas it seemed to have a positive effect in the starch coatings, through the enhancement of L. plantarum population after 7 storage days. Marín et al. (2016, 2017b) also observed little effect of several surfactants on the CFD retention on the grapes surface or improved cell adherence of $C$. sake. On the other hand, Hayek and Ibrahim (2013) reported that OA enhanced the growth of some LAB due to its

Table 1. Formulations applied on grapes containing or not coating-forming agents (biopolymer), oleic acid, and Lactobacillus plantarum.

\begin{tabular}{|c|c|c|c|}
\hline Formulation ${ }^{z}$ & Biopolymer $^{y}$ & Oleic $\operatorname{acid}^{\mathrm{x}}$ & L. plantarum $^{\mathrm{w}}$ \\
\hline $\mathrm{C}-\mathrm{W}$ & - & - & - \\
\hline C-LAB & - & - & + \\
\hline $\mathrm{NaC}$ & $\mathrm{NaC}$ & - & - \\
\hline $\mathrm{NaC}-\mathrm{OA}$ & $\mathrm{NaC}$ & + & - \\
\hline $\mathrm{NaC}+\mathrm{LAB}$ & $\mathrm{NaC}$ & - & + \\
\hline $\mathrm{NaC}-\mathrm{OA}+\mathrm{LAB}$ & $\mathrm{NaC}$ & + & + \\
\hline PS & PS & - & - \\
\hline PS-OA & PS & + & - \\
\hline $\mathrm{PS}+\mathrm{LAB}$ & PS & - & + \\
\hline PS-OA + LAB & PS & + & + \\
\hline
\end{tabular}

${ }^{\mathrm{z}} \mathrm{C}=$ control sample $(\mathrm{W}=$ water, noncoated, $\mathrm{LAB}=$ coated with lactic acid bacteria cell suspensions $) ; \mathrm{LAB}=$ lactic acid bacteria (L. plantarum) $\mathrm{NaC}=$ sodium caseinate; $\mathrm{OA}=$ oleic acid; $\mathrm{PS}=$ pregelatinized potato starch . ${ }^{\mathrm{y}} 2 \%(\mathrm{wt} / \mathrm{vol})$.

${ }^{\mathrm{x}} 1: 0.1$ (biopolymer:surfactant). "+" indicates when OA is present in the formulation, "-" when absent. w $5 \cdot 10^{7}$ colony-forming units/mL. "+" indicates when LAB is incorporated in the formulation, "-" when absent.

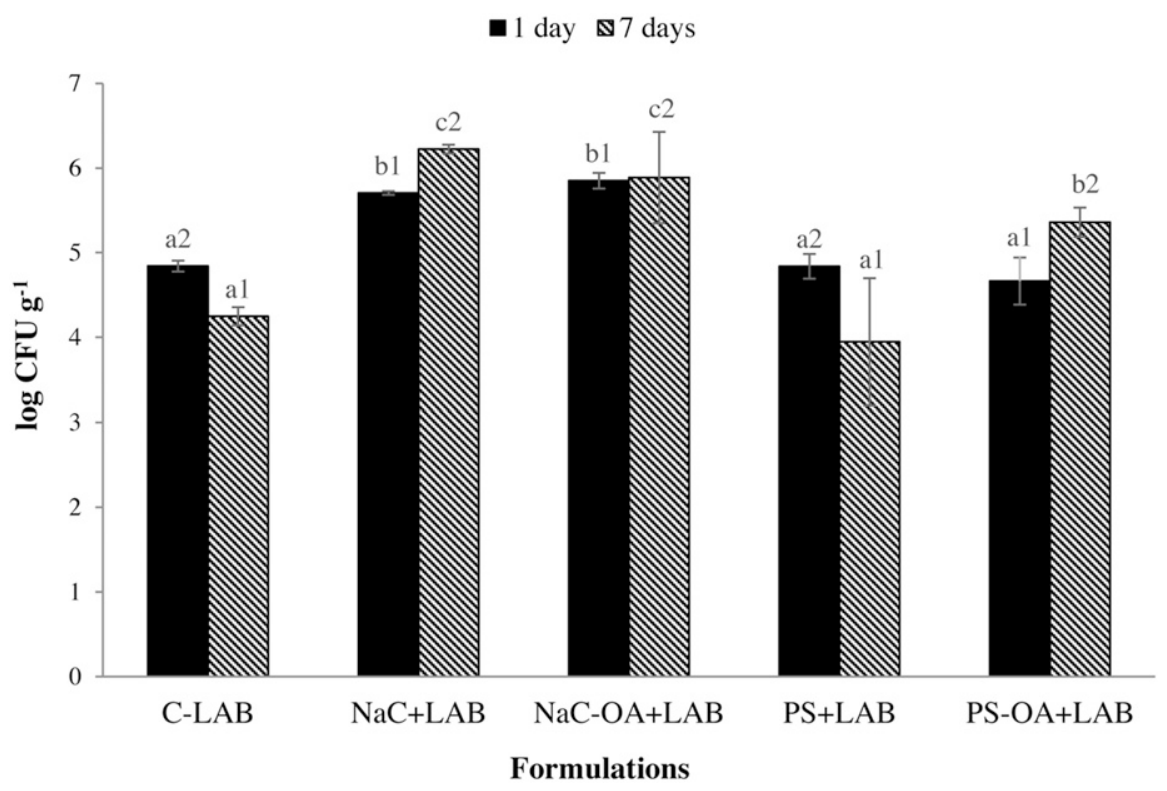

Fig. 1. Population counts of Lactobacillus plantarum on grape surface applied with different coatingforming dispersions at 1 and $7 \mathrm{~d}$ after application. Values are means (with standard deviations) of three replicates per treatment and storage time. Different superscripts $(a, b, c)$ and $(1,2)$ indicate significant differences determined using least significant difference test $(P<0.05)$ between formulations and storage time, respectively. $\mathrm{C}=$ control (water dispersion); $\mathrm{CFU}=$ colony-forming unit; $\mathrm{LAB}=L$. plantarum $; \mathrm{NaC}=$ sodium caseinate, $\mathrm{OA}=$ oleic acid; $\mathrm{PS}=$ pregelatinized potato starch .

incorporation into cell membranes, which improves their fluidity and offers protection from environmental conditions.

The preceding data confirm the ability of L. plantarum to first colonize fruit, which is a key factor to ensure a high population of the antagonist to fight against pathogenic fungi (McGuire and Dimitroglou, 1999), and to establish itself. Other authors have reported similar results studying the antifungal performance of $L$. plantarum. For instance, Trias et al. (2008) reported that ATCC 14917 strain population remained relatively stable after $142 \mathrm{~d}$ of postharvest storage at 0.5 to $1{ }^{\circ} \mathrm{C}$ in inoculated apple wounds. Likewise, Roselló et al. (2013) described good results with different strains of this species used for biopreservation of apples and pears against Erwinia amylovora for at least 1 week at $25^{\circ} \mathrm{C}$.

In general, it could be said that coatingforming agents promoted the ability of $L$. plan- tarum to colonize the grape surface, especially when $\mathrm{NaC}$ was used as their main compound. This confirms the good compatibility between L. plantarum and the tested coating-forming agents, suggesting that proteins could be a more suitable source of nutrients, as previously reported by Marín et al. (2016).

The antifungal capacity of L. plantarum against $B$. cinerea on grapes is reflected in Fig. 2, which shows the percentages of reduction of the incidence and severity of the infection achieved with the bioactive coatings, as compared with the control sample (without LAB cells). In contrast with the cell population data, the best inhibition of the fungal action was reached with the starch coating without OA, which led to a $100 \%$ reduction of infection and significantly $(P<$ $0.05)$ improved the results obtained with LAB without coating (C-LAB). No significant differences were observed for $\mathrm{NaC}-\mathrm{OA}$ 
and PS-OA formulations when compared with the control, whereas the formulation based on $\mathrm{NaC}$ without surfactant showed the lowest inhibitory effect. In this sense, Sánchez-González et al. (2013, 2014) reported a greater production of bacteriocins by some strains of LAB in polysaccharide than in protein media. In both studies, greater bacteriocin production implied a better antilisterial effect and could also have some antifungal action. With respect to the reduction of infection severity, formulations containing $L$. plantarum achieved values that ranged between $92 \%$ and $100 \%$. All combinations of CFDs significantly reduced percentage of fruit surface affected by Botrytis infection in comparison with control. No coherent role of $\mathrm{OA}$ on the antifungal activity of $L$. plantarum was observed for starch and protein systems, probably due to the differences in antifungal metabolites induced by the components in PS and $\mathrm{NaC}$ matrices. Likewise, the coating components also can affect fungal growth to different extents. Therefore, the interactions of the coating compounds both with the antagonist and the pathogen, might have influence in the resulting antifungal activity.

In every case, the levels of infection incidence and severity, achieved when $L$. plantarum was incorporated into the coatings or water suspensions, were lower than those reached in the $\mathrm{C}-\mathrm{W}$ control samples, which confirmed the potential of the ATCC 14917 $L$. plantarum strain to control $B$. cinerea by its ability to produce antifungal metabolites on the fruit surface. Other studies also reported the effectiveness of L. plantarum strains against fruit fungal pathogens. Sathe et al. (2007) showed a strong inhibitory effect against $B$. cinerea in cucumber wounds inoculated with $L$. plantarum CUK501. Trias et al. (2008) observed that different L. plantarum strains were effective against $B$. cinerea, among other pathogens. These authors reported that, in in vitro tests, the production of organic acids was the main mechanism of action against the spoilage fungi. Organic acids might cause an acidification of the fruit surface that could negatively affect the fungal growth and development. Production of lactic, acetic, and succinic acids or ethanol were measured in several strains of $L$. plantarum grown under aerobic and anaerobic conditions, and showed little differences in production of these acids between growing conditions (Smetanková et al., 2012; Valan Arasu et al., 2013). In our study, even though initial growth of $L$. plantarum was done under anaerobic conditions, because the film layer on the fruit surface is so thin, it was assumed that the environment became aerobic, providing the bacterium multiple opportunities to produce antimicrobial compounds, and also perhaps different types of compounds.

Fig. 3 shows weight loss of grapes coated with the different CFD containing or not $L$. plantarum, after $9 \mathrm{~d}$ of storage at $20{ }^{\circ} \mathrm{C}$ and $85 \%$ RH. The fruit weight loss observed during this period is a physical process caused by the migration of water from the plant tissues to the environment (Sánchez-

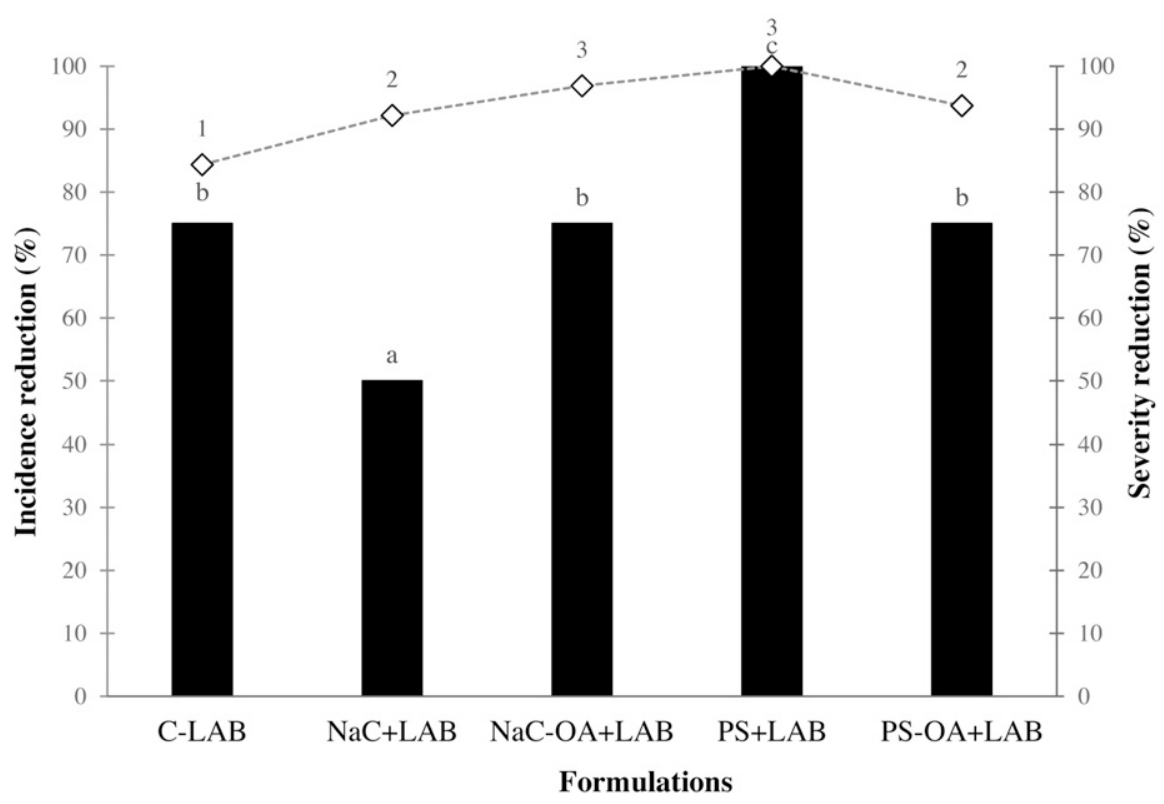

Fig. 2. Percentage of reduction of Botrytis cinerea infection in reference to water control after $7 \mathrm{~d}$ of storage, by application of Lactobacillus plantarum on grapes using different coating-forming dispersions: incidence (bars) and severity (points). Values are means of three replicates. Different superscripts $(a, b, c)$ and $(1,2,3)$ indicate significant differences determined using least significant difference test $(P<0.05)$ between formulations for reduction of incidence and severity, respectively. $\mathrm{C}=$ control (water dispersion) $\mathrm{LAB}=$ L. plantarum $; \mathrm{NaC}=$ sodium caseinate, $\mathrm{OA}=$ oleic acid; $\mathrm{PS}=$ pregelatinized potato starch.

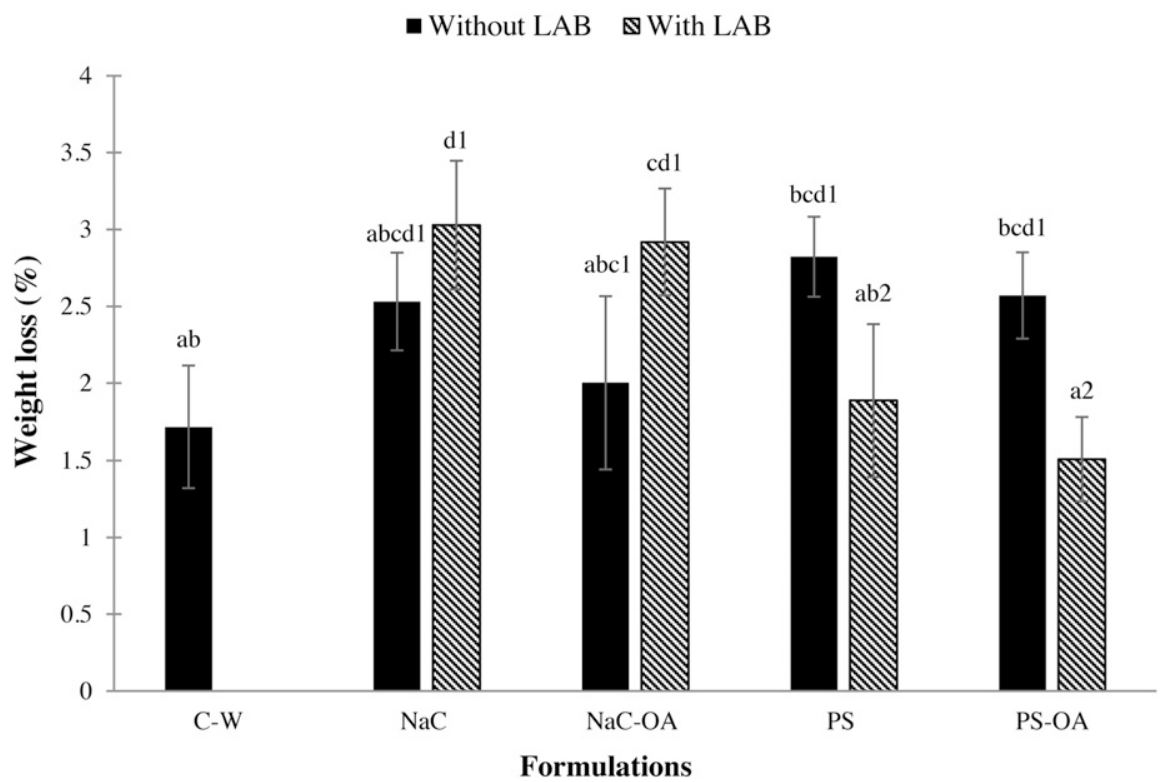

Fig. 3. Berry weight loss after $9 \mathrm{~d}$ of storage of uncoated grapes or coated with the different dispersions containing or not Lactobacillus plantarum (LAB). Values are means of three replicates (with standard deviations). Different superscripts $(a, b, c, d)$ and $(1,2)$ indicate significant differences determined using least significant difference test $(P<0.05)$ between formulations (letters), and for the same formulation, with and without LAB (numbers). $\mathrm{C}=$ control (water dispersion); $\mathrm{LAB}=$ L. plantarum; $\mathrm{NaC}=$ sodium caseinate, $\mathrm{OA}=$ oleic acid PS $=$ pregelatinized potato starch .

González et al., 2011), with great influence of $\mathrm{RH}$ and postharvest biological processes (Kader, 2002). After 9 storage days, weight loss ranged from $1.5 \%$ to $3.0 \%$ and, in general, there were no remarkable differences $(P>0.05)$ with respect to uncoated control samples. This suggests that the applied coatings, hydrophilic in nature, only exerted a light barrier on the fruit surface. The presence of OA in the formulations did not reduce sample weight loss despite an enhancement in coating hydrophobicity (Pasquali et al., 2008). In this sense, some authors have observed an improvement in water vapor barrier properties of starch films when fatty acids were incorporated (Jiménez 
et al., 2013; Marín et al., 2017b). Vargas et al. (2006) also reported that the incorporation of OA to chitosan coatings increased the water vapor resistance of strawberries. However, there were no significant differences $(P>$ 0.05 ) in weight loss between samples coated with $\mathrm{NaC}$ or PS formulations with and without surfactant.

Adding LAB to coatings had a variable effect on grape weight loss depending on the biopolymer type. Although in the case of protein-based coatings those formulations containing $L$. plantarum gave rise to higher (but not significant) weight losses, coatings based on starch showed significantly lower values when the bacteria was incorporated.

In practical terms, the observed weight losses could be considered as low because in no treatment was more than $5 \%$, which, according to Deng et al. (2006) and Valverde et al. (2005) is considered the acceptable limit in table grapes for retail purposes. Likewise, data are in line with those reported by other authors who previously applied polysaccharide-based coatings on grapes (Aloui et al., 2014; Pastor et al., 2011). Because few differences between coated and uncoated grapes were observed, it could be concluded that the formed coatings were too thin to seriously affect the fruit's water vapor exchanges.

Color parameters of coated and uncoated samples at the initial time and after $9 \mathrm{~d}$ of storage days are shown in Fig. 4. In general, color coordinates of the sample batches associated with each treatment exhibited differences due to the natural variability in the raw material. After $9 \mathrm{~d}$ of storage, a general decrease was observed in luminosity $\left(\mathrm{L}^{*}\right)$ and chroma $\left(\mathrm{C}_{\mathrm{ab}}{ }^{*}\right)$, but was significant only for some treatments ( $\mathrm{NaC}+\mathrm{LAB}$, PS$\mathrm{OA})$. No clear tendency was observed for hue $\left(\mathrm{h}_{\mathrm{ab}} *\right)$ values, which showed high variability with values ranging between 187 and 240 (blueish colors associated with the anthocyanin content). The decrease in $\mathrm{L}^{*}$ and $\mathrm{C}_{\mathrm{ab}}$ * values throughout the storage time could be attributed to the progressive ripening process causing water loss and browning of the tissues (Kader, 2002). The most significant decrease in luminosity or chroma was observed in uncoated samples for $\mathrm{L}^{*}$, and in samples coated with PS formulations for $\mathrm{C}^{*}$. However, considering the variability of raw material and the limited change in the parameters, no clear conclusions could be obtained about the effect of the different coatings on the color development during storage, although for some treatments a delay in the color changes could be assumed, in comparison with the uncoated control samples. A delay in color changes of coated grapes was observed by other authors. Pastor et al. (2011) and Sánchez-González et al. (2011) observed a reduced decrease in luminosity and hue of grapes coated with hydroxypropylmethylcellulose and chitosan. Likewise, more recently Oh et al. (2017) and Lemes et al. (2017) observed significant delays in color changes when chitosan coating emulsions or gelatinbased coatings were applied on grapes.

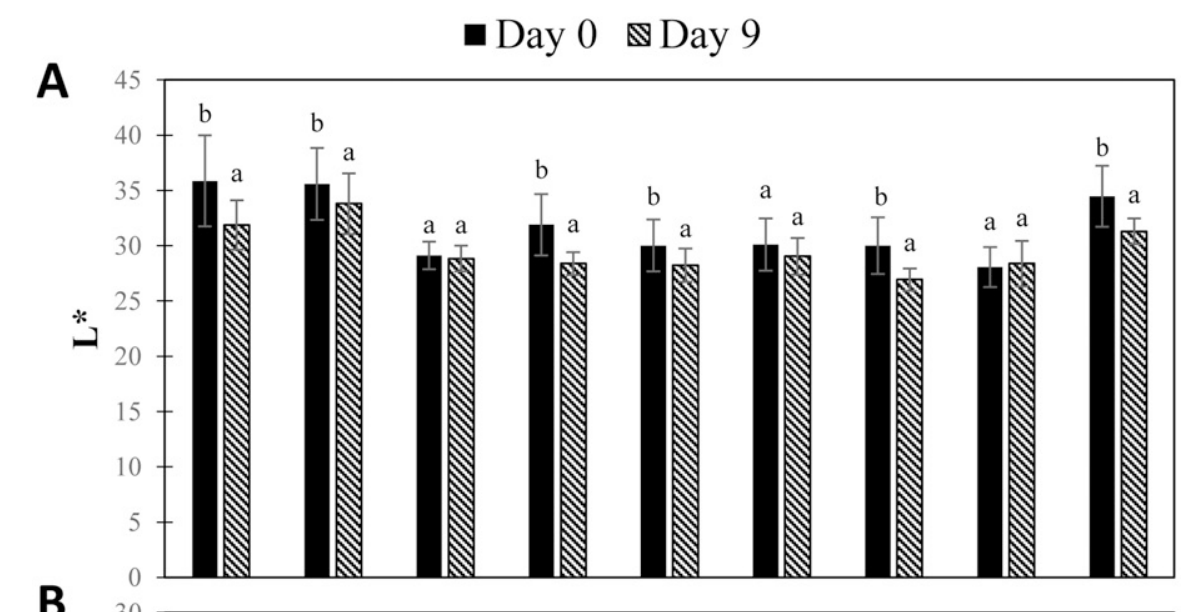

B
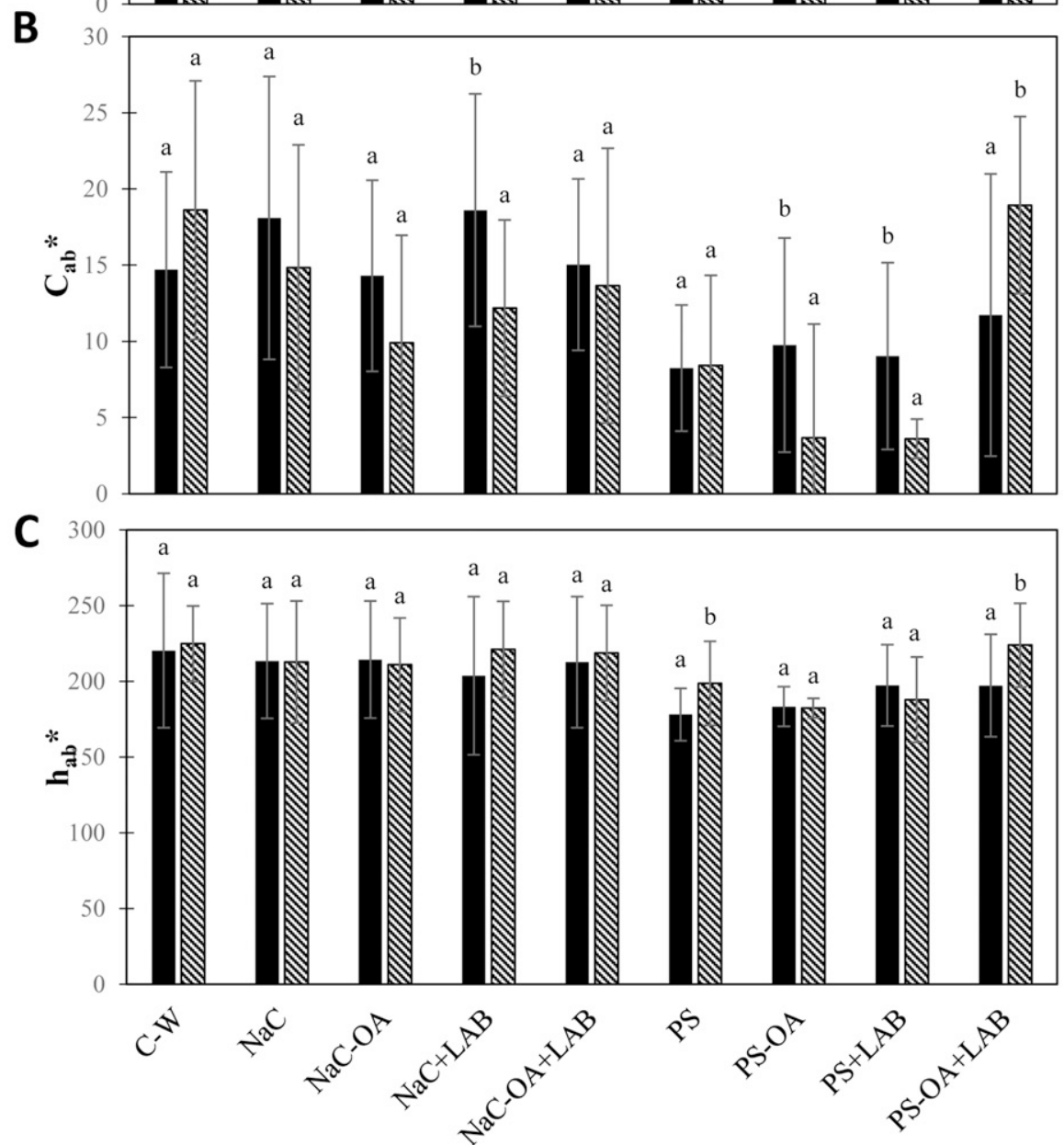

Formulations

Fig. 4. Luminosity $\left(\mathrm{L}^{*}\right)(\mathbf{A})$, chroma $\left(\mathrm{C}_{\mathrm{ab}}{ }^{*}\right)(\mathbf{B})$, and hue $\left(\mathrm{h}_{\mathrm{ab}} *\right)(\mathbf{C})$ of grapes at initial time and after 9 storage days for uncoated and coated grapes with the different formulations containing or not Lactobacillus plantarum. Values are means of three replications (with standard deviations). Different superscripts $(\mathrm{a}, \mathrm{b})$ indicate significant differences determined using least significant difference test $(P<$ 0.05 ) for $\mathrm{L}^{*}, \mathrm{C}_{\mathrm{ab}} *$, and $\mathrm{h}_{\mathrm{ab}}{ }^{*}$ between day 0 and day 9 for each formulation. $\mathrm{C}=$ control (water dispersion); $\mathrm{LAB}=$ L. plantarum $; \mathrm{NaC}=$ sodium caseinate, $\mathrm{OA}=$ oleic acid; $\mathrm{PS}=$ pregelatinized potato starch.

Texture is a key factor to maintain fruit postharvest quality and has a strong impact on acceptability by consumers (Aloui et al., 2014). The initial firmness value of the grapes was of $32 \pm 13 \mathrm{~N}$. A trend toward a decrease in firmness was observed in both uncoated and coated grapes after $9 \mathrm{~d}$ in storage (Table 2). Loss of firmness can be explained by the breakdown of pectins and other polysaccharides causing a progressive softening of the tissues, together with the water loss (Aloui et al., 2014; Kader, 2002). The statistical analysis revealed no significant differences $(P>0.05)$ between uncoated and coated samples. Grapes treated with PS-OA, showed significantly higher firmness than 
Table 2. Firmness, soluble solids content (SSC), titratable acidity (TA), and maturity index (MI) of uncoated grapes or coated with coating-forming dispersions containing or not Lactobacillus plantarum after $9 \mathrm{~d}$ of storage.

\begin{tabular}{lcccr}
\hline Formulation $^{\mathrm{z}}$ & ${\text { Firmness }(\mathrm{N})^{\mathrm{y}}}$ & SSC $(\%)$ & TA $^{\mathrm{x}}$ & MI \\
\hline $\mathrm{C}-\mathrm{W}$ & $23(7)^{\mathrm{ab}}$ & $19.7(1.3)^{\mathrm{a}}$ & $0.309(0.004)^{\mathrm{ab}}$ & $68(5)^{\mathrm{bc}}$ \\
$\mathrm{NaC}$ & $20(5)^{\mathrm{a}}$ & $19.93(0.15)^{\mathrm{a}}$ & $0.343(0.007)^{\mathrm{d}}$ & $58.3(1.2)^{\mathrm{a}}$ \\
$\mathrm{NaC}-\mathrm{OA}$ & $21(6)^{\mathrm{a}}$ & $19.6(0.6)^{\mathrm{a}}$ & $0.314(0.012)^{\mathrm{ab}}$ & $62.6(1.7)^{\mathrm{ab}}$ \\
$\mathrm{NaC}+\mathrm{LAB}$ & $24(8)^{\mathrm{ab}}$ & $20.07(0.06)^{\mathrm{a}}$ & $0.297(0.017)^{\mathrm{a}}$ & $67(4)^{\mathrm{c}}$ \\
$\mathrm{NaC}-\mathrm{OA}+$ LAB & $22(5)^{\mathrm{ab}}$ & $19.6(0.10)^{\mathrm{a}}$ & $0.331(0.005)^{\mathrm{cd}}$ & $59.2(0.8)^{\mathrm{a}}$ \\
PS & $23(7)^{\mathrm{ab}}$ & $19.33(0.14)^{\mathrm{a}}$ & $0.318(0.007)^{\mathrm{bc}}$ & $60.8(1.0)^{\mathrm{ab}}$ \\
PS-OA & $27(12)^{\mathrm{b}}$ & $19.33(0.15)^{\mathrm{a}}$ & $0.323(0.013)^{\mathrm{bc}}$ & $60(3)^{\mathrm{ab}}$ \\
PS + LAB & $26(11)^{\mathrm{ab}}$ & $19.43(0.12)^{\mathrm{a}}$ & $0.324(0.018)^{\mathrm{bc}}$ & $60(4)^{\mathrm{ab}}$ \\
PS-OA + LAB & $20(8)^{\mathrm{a}}$ & $20.0(0.10)^{\mathrm{a}}$ & $0.333(0.005)^{\mathrm{cd}}$ & $60.1(0.8)^{\mathrm{ab}}$ \\
\hline
\end{tabular}

${ }^{\mathrm{z}} \mathrm{C}-\mathrm{W}=$ control $; \mathrm{LAB}=$ L. plantarum $; \mathrm{NaC}=$ sodium caseinate $\mathrm{OA}=$ oleic acid; $\mathrm{PS}=$ pregelatinized potato starch.

${ }^{\mathrm{y}}$ Different superscripts $(\mathrm{a}, \mathrm{b})$ within the same column indicate significant differences determined using least significant difference test $(P<0.05)$ between formulations. Values are means of three replicates (with standard deviations).

${ }^{x_{g}}$ citric acid per $100 \mathrm{~g}$ of grapes.

grapes coated with $\mathrm{NaC}$, NaC-OA, and PS$\mathrm{OA}+\mathrm{LAB}$ (Table 2). Similar results were obtained by de Oliveira et al. (2014), who did not observe firmness differences between noncoated and chitosan-coated grapes stored at room temperature. Likewise, Pastor et al. (2011) applied hydroxypropylmethylcellulosebased coatings to grapes and they did not find differences in the firmness of uncoated and coated grapes after cold storage. In contrast, other authors found greater loss of firmness in uncoated grapes compared with the coated ones (Aloui et al., 2014; SánchezGonzález et al., 2011; Valverde et al., 2005). These different behaviors might be due to different environmental conditions during storage, the nature of biopolymers used as coatings, and even the grape cultivar. Moreover, contrary to that reported by Aloui et al. (2014), no clear coherence between weight loss and firmness loss was observed, because samples coated with PS-OA+LAB formulation exhibited the lowest weight loss and present the lowest firmness by the end of storage.

Initial grape $\mathrm{SSC}$ was $18.6 \pm 0.3$ and, as shown in Table 2, an increase in SSC content occurred after $9 \mathrm{~d}$ of storage in every sample. The increase ranged from 0.7 to 1.4 without significant differences $(P>0.05)$ between treatments. The increase in SSC is the result of starch hydrolysis and its conversion into sugars during the ripening process. Likewise, de Oliveira et al. (2014) and Pastor et al. (2011) observed an increase in SSC during grape storage but no differences among berries coated or not with chitosan was detected. In line with the increase in sugar content, a decrease in the acidity from the initial value $(0.390 \pm 0.004)$ was observed due to the degradation of organic acids. In general, a slight trend toward lower reductions of acidity was observed when the coating formulations were applied. All formulations based on PS with and without $L$. plantarum, as well as $\mathrm{NaC}$ and $\mathrm{NaC}$ $\mathrm{OA}+\mathrm{LAB}$, delayed the degradation of acids when compared with the control sample, suggesting a decrease in the fruit respiration metabolism, as previously reported by Lemes et al. (2017). Coatings that better maintained acidity were $\mathrm{NaC}, \mathrm{NaC}-\mathrm{OA}+$ $\mathrm{LAB}$, and $\mathrm{PS}-\mathrm{OA}+\mathrm{LAB}$. The $\mathrm{MI}$ of the grapes showed a clear increase from the initial value $(47.4 \pm 0.8)$ due to the changes in the sugar and acid contents. In all cases, coated samples had lower MI values than control, but it was significant $(P<0.05)$ only in samples coated with $\mathrm{NaC}$ and $\mathrm{NaC}$ $\mathrm{OA}+\mathrm{LAB}$ (Table 2).

For most quality parameters evaluated in this study, few differences among coated and noncoated samples were observed over the assessed storage period, suggesting that the formulations had minimal impact on the preservation of food quality. Differences in the coating extensibility on the fruit surface and the subsequent degree of coating uniformity have been pointed as one of the possible reasons for this observation (Pastor et al., 2011; Vargas et al., 2006). Nevertheless, the coatings were able to improve the performance of $L$. plantarum as an antifungal agent. Thus, L. plantarum might be a promising candidate to develop active biopolymerbased coatings for biopreservation of grapes. In this respect, it should be kept in mind that studying specific interactions between $\mathrm{LAB}$ and fungi is highly complicated mainly because bacterial metabolites can act synergistically on the antifungal activity (Schnürer and Magnusson, 2005).

This strategy has the advantage that the bioactive ( $L$. plantarum) complies with all recommendations for food products and could provide a basis for further studies aimed at deepening the mechanisms whereby L. plantarum exerts its antifungal activity, testing their inhibitory effect under different storage conditions and optimizing the coating formulations to improve its performance to a higher extent.

\section{Literature Cited}

Aloui, H., K. Khwaldia, L. Sánchez-González, L. Muneret, C. Jeandel, M. Hamdi, and S. Desobry. 2014. Alginate coatings containing grapefruit essential oil or grapefruit seed extract for grapes preservation. Intl. J. Food Sci. Technol. 49:952959.

Cañamás, T.P., I. Viñas, R. Torres, J. Usall, C. Solsona, and N. Teixidó. 2011. Field applica- tions of improved formulations of Candida sake CPA-1 for control of Botrytis cinerea in grapes. Biol. Control 56:150-158.

Crowley, S., J. Mahony, and D. van Sinderen. 2013. Current perspectives on antifungal lactic acid bacteria as natural bio-preservatives. Trends Food Sci. Technol. 33:93-109.

Dean, R., J.A.L. Van Kan, Z.A. Pretorius, K.E. Hammond-Kosack, A. Di Pietro, P.D. Spanu, J.J. Rudd, M. Dickman, R. Kahmann, J. Ellis, and G.D. Foster. 2012. The Top 10 fungal pathogens in molecular plant pathology. Mol. Plant Pathol. 13:414-430.

Deng, Y., Y. Wu, and Y. Li. 2006. Physiological responses and quality attributes of 'Kyoho' grapes to controlled atmosphere storage. Lebensm. Wiss. Technol. 39:584-590.

de Oliveira, C., M. Magnani, C. de Sales, A. de Souza Pontes, C. Campos-Takaki, T. Stamford, and E. de Souza. 2014. Effects of chitosan from Cunninghamella elegans on virulence of post-harvest pathogenic fungi in table grapes (Vitis labrusca L.). Intl. J. Food Microbiol. 171:54-61.

de Vries, M., E. Vaughan, M. Kleerebezem, and W. de Vos. 2006. Lactobacillus plantarumsurvival, functional and potential probiotic properties in the human intestinal tract. Intl. Dairy J. 16:1018-1028.

Dong, A., V. Thuy Ho, R. Lo, N. Bansal, and M. Turner. 2017. A genetic diversity study of antifungal Lactobacillus plantarum isolates. Food Control 72:83-89.

Ebrahimi, B., R. Mohammadi, M. Rouhi, A.M. Mortazavian, S. Shojaee-Aliabadi, and M.R. Koushki. 2018. Survival of probiotic bacteria in carboxymethyl cellulose-based edible film and assessment of quality parameters. Lebensm. Wiss. Technol. 87:54-60.

Gajbhiye, M. and B. Kapadnis. 2016. Antifungalactivity-producing lactic acid bacteria as biocontrol agents in plants. Biocontrol Sci. Technol. 26:1451-1470.

Ghafoor, K., J. Park, and Y. Choi. 2010. Optimization of supercritical fluid extraction of bioactive compounds from grape (Vitis labrusca B.) peel by using response surface methodology. Innov. Food Sci. Emerg. Technol. 11:485-490.

Gupta, R. and S. Srivastava. 2014. Antifungal effect of antimicrobial peptides (AMPs LR14) derived from Lactobacillus plantarum strain $\mathrm{LR} / 14$ and their applications in prevention of grain spoilage. Food Microbiol. 42:1-7.

Hartman, J.R. and C.A. Kaiser. 2008. Fruit rots of grapes. Plant Pathology Fact Sheet. University of Kentucky College of Agriculture, Lexington, KY.

Hayek, S.A. and S.A. Ibrahim. 2013. Current limitations and challenges with lactic acid bacteria: A review. Food Nutr. Sci. 4:73-87.

Hodges, R., J. Buzby, and B. Bennett. 2011. Postharvest losses and waste in developed and less developed countries: Opportunities to improve resource use. J. Agr. Sci. 149:37-45.

Janisiewicz, W.J. and L. Korsten. 2002. Biological control of postharvest diseases of fruits. Annu. Rev. Phytopathol. 40:411-441.

Jiménez, A., M.J. Fabra, P. Talens, and A. Chiralt. 2013. Phase transitions in starch based films containing fatty acids. Effect on water sorption and mechanical behavior. Food Hydrocoll. 30:408-418.

Jiwanit, P., T. Pitakpornpreecha, S. Pisuchpen, and W. Leelasuphakul. 2018. The use of Aloe vera gel coating supplemented with Pichia guilliermondii BCC5389 for enhancement of defense-related gene expression and secondary metabolism in mandarins to prevent postharvest losses from green mold rot. Biol. Control 117:43-51. 
Kader, A.A. 2002. Postharvest biology and technology: An overview, p. 39-47. In: A. Kader (ed.). Postharvest technology of horticultural crops. University of California, Agriculture and Natural Resources, Oakland, CA.

Lamont, J.R., O. Wilkins, M. Bywater-Ekegärd, and D.L. Smith. 2017. From yogurt to yield: Potential applications of lactic acid bacteria in plant production. Soil Biol. Biochem. 111:1-9.

Lemes, G., N. Marchiore, T. Moreira, T. Da Silva, C. Sayer, M. Shirai, O. Gonçalves, A. Gozzo, and F. Leimann. 2017. Enzymatically crosslinked gelatin coating added of bioactive nanoparticles and antifungal agent: Effect on the quality of Benitaka grapes. Lebensm. Wiss. Technol. 84:175-182.

Magnusson, J., K. Ström, S. Roos, J. Sjögren, and J. Schnürer. 2003. Broad and complex antifungal activity among environmental isolates of lactic acid bacteria. FEMS Microbiol. Lett. 219:129135.

Marín, A., M. Cháfer, L. Atarés, A. Chiralt, R. Torres, J. Usall, and N. Teixidó. 2016. Effect of different coating-forming agents on the efficacy of the biocontrol agent Candida sake CPA-1 for control of Botrytis cinerea on grapes. Biol. Control 96:108-119.

Marín, A., L. Atarés, and A. Chiralt. 2017a. Improving function of biocontrol agents incorporated in antifungal fruit coatings: A review. Biocontrol Sci. Technol. 27:1220-1241.

Marín, A., L. Atarés, and A. Chiralt. 2017b. Properties of biopolymer dispersions and films used as carriers of the biocontrol agent Candida sake CPA-1. Lebensm. Wiss. Technol. 79:60-69.

McGuire, R.G. and D.A. Dimitroglou. 1999. Evaluation of shellac and sucrose ester fruit coating formulations that support biological control of post-harvest grapefruit decay. Biocontrol Sci. Technol. 9:53-65.

Nicolosi, E., F. Ferlito, M. Amenta, T. Russo, and P. Rapisarda. 2018. Changes in the quality and antioxidant components of minimally processed table grapes during storage. Scientia Hort. 232:175-183.

Oh, Y.A., Y.J. Oh, A.Y. Song, J.S. Won, K.B. Song, and S.C. Min. 2017. Comparison of effectiveness of edible coatings using emulsions containing lemongrass oil of different size droplets on grape berry safety and preservation. Lebensm. Wiss. Technol. 75:742-750.

Palou, L., M. Serrano, D. Martinez-Romero, and D. Valero. 2010. New approaches for postharvest quality retention of table grapes. Fresh Prod. 4:103-110.

Palou, L., S. Valencia-Chamorro, and M.B. PérezGago. 2015. Antifungal edible coatings for fresh citrus fruit: A review. Coatings. 5:962986.

Parafati, L., A. Vitale, C. Restuccia, and G. Cirvilleri. 2016. The effect of locust bean gum (LBG)-based edible coatings carrying biocontrol yeasts against Penicillium digitatum and Penicillium italicum causal agents of postharvest decay of mandarin fruit. Food Microbiol. 58:87-94.

Pasquali, R., M. Taurozzi, and C. Bregni. 2008. Some considerations about the hydrophilic - lipophilic balance system. Intl. J. Pharm. 356: 44-51.

Pastor, C., L. Sánchez-González, A. Marcilla, A. Chiralt, M. Cháfer, and C. González-Martínez. 2011. Quality and safety of table grapes coated with hydroxypropylmethylcellulose edible coatings containing propolis extract. Postharvest Biol. Technol. 60:64-70.

Pereira, J.O., J. Soares, S. Sousa, A. Madureira, A. Gomes, and M. Pintado. 2016. Edible films as carrier for lactic acid bacteria. Lebensm. Wiss. Technol. 73:543-550.

Prema, P., D. Smila, A. Palavesam, and G. Immanuel. 2010. Production and characterization of an antifungal compound (3-Phenyllactic Acid) produced by Lactobacillus plantarum strain. Food Bioprocess Technol. 3:379-386.

Reglinski, T., P.A.G. Elmer, J.T. Taylor, P.N. Wood, and S.M. Hoyte. 2010. Inhibition of Botrytis cinerea growth and suppression of botrytis bunch rot in grapes using chitosan. Plant Pathol. 59:882-890.

Roselló, G., A. Bonaterra, J. Francés, L. Montesinos, E. Badosa, and E. Montesinos. 2013. Biological control of fire blight of apple and pear with antagonistic Lactobacillus plantarum. Eur. J. Plant Pathol. 137:621-633.

Sánchez-González, L., C. Pastor, M. Vargas, A. Chiralt, C. González-Martínez, and M. Cháfer. 2011. Effect of hydroxypropylmethylcellulose and chitosan coatings with and without bergamot essential oil on quality and safety of coldstored grapes. Postharvest Biol. Technol. 60:57-63.

Sánchez-González, L., J.I. Quintero Saavedra, and A. Chiralt. 2013. Physical properties and antilisterial activity of bioactive edible films containing Lactobacillus plantarum. Food Hydrocoll. 33:92-98.

Sánchez-González, L., J.I. Quintero Saavedra, and A. Chiralt. 2014. Antilisterial and physical properties of biopolymer films containing lactic acid bacteria. Food Control 35:200-206.

Sangmanee, P. and T. Hongpattarakere. 2014. Inhibitory of multiple antifungal components produced by Lactobacillus plantarum K35 on growth, aflatoxin production and ultrastructure alterations of Aspergillus flavus and Aspergillus parasiticus. Food Control 40:224-233.

Sathe, S.J., N.N. Nawani, P.K. Dhakephalkar, and B.P. Kapadnis. 2007. Antifungal lactic acid bacteria with potential to prolong shelf-life of fresh vegetables. J. Appl. Microbiol. 103:26222628.

Schnürer, J. and J. Magnusson. 2005. Antifungal lactic acid bacteria as biopreservatives. Trends Food Sci. Technol. 16:70-78.

Seiber, J.N., J. Coats, S. Duke, and A.D. Gross. 2014. Biopesticides: State of the art and future opportunities. J. Agr. Food Chem. 62:1161311619.

Sharma, R.R., D. Singh, and R. Singh. 2009. Biological control of postharvest diseases of fruits and vegetables by microbial antagonists: A review. Biol. Control 50:205-221.

Sjögren, J., J. Magnusson, A. Broberg, J. Schnürer, and L. Kenne. 2003. Antifungal 3-hydroxy fatty acids from Lactobacillus plantarum MiLAB 14. Appl. Environ. Microbiol. 69:7554-7557.

Smetanková, J., Z. Hladíková, F. Valach, M. Zimanová, Z. Kohajdová, G. Greif, and M. Greifová. 2012. Influence of aerobic and anaerobic conditions on the growth and metabolism of selected strains of Lactobacillus plantarum. Acta Chim. Slov. 5:204-210.

Sortino, G., A. Allegra, R. Passafiume, G. Gianguzzi, G. Gullo, and A. Gallotta. 2017. Postharvest application of sulphur dioxide fumigation to improve quality and storage ability of "Red Globe" grape cultivar during long cold storage. Chem. Eng. Trans. 58:403-408.

Spadaro, D. and M.L. Gullino. 2004. State of the art and future prospects of the biological control of postharvest fruit diseases. Intl. J. Food Microbiol. 91:184-194.

Ström, K., J. Sjögren, A. Broberg, and J. Schnürer. 2002. Lactobacillus plantarum MiLAB 393 produces the antifungal cyclic dipeptides cyclo(1-phe-1-pro) and cyclo(1-phe-trans-4-oh1-pro) and 3-phenyllactic acid. Appl. Environ. Microbiol. 68:4322-4327.

Trias, R., L. Bañeras, E. Montesinos, and E. Badosa. 2008. Lactic acid bacteria from fresh fruit and vegetables as biocontrol agents of phytopathogenic bacteria and fungi. Intl. Microbiol. 11:231-236.

Usall, J., R. Torres, and N. Teixidó. 2016. Biological control of postharvest diseases on fruit: A suitable alternative? Curr. Opin. Food Sci. 11:51-55.

Valan Arasu, M., M. Jung, S. Ilavenil, M. Jane, D. Kim, K. Lee, H. Park, T. Hur, G. Choi, Y. Lim, N. Al-Dhabi, and K. Choi. 2013. Isolation and characterization of antifungal compound from Lactobacillus plantarum KCC-10 from forage silage with potential beneficial properties. J. Appl. Microbiol. 115:1172-1185.

Valverde, J.M., D. Valero, D. Martínez-Romero, F. Guillén, S. Castillo, and M. Serrano. 2005. Novel edible coating based on Aloe vera gel to maintain table grape quality and safety. J. Agr. Food Chem. 53:7807-7813.

Vargas, M., A. Albors, A. Chiralt, and C. González-Martínez. 2006. Quality of coldstored strawberries as affected by chitosanoleic acid edible coatings. Postharvest Biol. Technol. 41:164-171.

Yang, E.J. and H.C. Chang. 2010. Purification of a new antifungal compound produced by Lactobacillus plantarum AF1 isolated from kimchi. Intl. J. Food Microbiol. 139:56-63.

Watanabe, M., S. van der Veen, H. Nakajima, and T. Abee. 2012. Effect of respiration and manganese on oxidative stress resistance of Lactobacillus plantarum WCFS1. Microbiology 158:293-300.

Zamani-Zadeh, M., S. Soleimanian-Zad, M. Sheikh-Zeinoddin, and S. Goli. 2014. Integration of Lactobacillus plantarum A7 with thyme and cumin essential oils as a potential biocontrol tool for gray mold rot on strawberry fruit. Postharvest Biol. Technol. 92:149-156. 